\title{
PERENCANAAN TRAYEK ANGKUTAN MENUJU KAWASAN WISATA KALIURANG-MERAPI DI KABUPATEN SLEMAN
}

\author{
Glendys Asri Aprianti Sangadji \\ Magister Teknik Sipil \\ Program Pascasarjana \\ Universitas Atma Jaya Yogyakarta \\ Jln. Babarsari No. 44, Yogyakarta, 55281 \\ glendyssangadji97@gmail.com
}

\author{
Imam Basuki \\ Magister Teknik Sipil \\ Program Pascasarjana \\ Universitas Atma Jaya Yogyakarta \\ Jln. Babarsari No. 44, Yogyakarta, 55281 \\ imam.basuki@uajy.ac.id
}

\begin{abstract}
The Kaliurang-Merapi tourist area is a tourist area in the Special Region of Yogyakarta Province with the highest number of tourist visits. This area has not been served by public transportation, so it is necessary to plan public transportation routes to the Kaliurang-Merapi tourist area. In this study, the planning of public transport routes to serve the Kaliurang-Merapi Tourism Area is carried out. The analysis is performed using quantitative methods on the number of transportation needs, vehicle operating costs, and passenger fares. There are 3 planned routes, namely Route 1 with a length of $14 \mathrm{~km}$, Route 2 with a length of $20.3 \mathrm{~km}$, and Route 3 with a length of $23.6 \mathrm{~km}$. This study proposes a tariff per passenger per trip of IDR 7,000-IDR 10,000 for Route 1, IDR 7,000-IDR 15,000 for Route 2, and IDR 8,000-19000 for Route 3.
\end{abstract}

Keywords: tourist area; public transportation; public transport routes; passenger fares.

\begin{abstract}
Abstrak
Kawasan wisata Kaliurang-Merapi adalah suatu kawasan wisata di Provinsi Daerah Istimewa Yogyakarta dengan jumlah kunjungan wisatawan terbanyak. Kawasan ini belum dilayani oleh angkutan umum, sehingga diperlukan perencanaan trayek angkutan umum menuju kawasan wisata Kaliurang-Merapi ini. Pada studi ini dilakukan perencanaan trayek angkutan umum untuk melayani Kawasan Wisata Kaliurang-Merapi. Analisis dilakukan dengan menggunakan metode kuantitatif terhadap kebutuhan jumlah angkutan, biaya operasional kendaraan, dan tarif penumpang. Terdapat 3 trayek yang direncanakan, yaitu Trayek 1 sepanjang 14 km, Trayek 2 sepanjang 20,3 km, dan Trayek 3 sepanjang 23,6 km. Studi ini mengusulkan Tarif per penumpang per trip sebesar Rp7.000-Rp10.000 untuk Trayek 1, Rp7.000-Rp15.000 untuk Trayek 2, dan Rp8.000-Rp19.000 untuk Trayek 3.
\end{abstract}

Kata-kata kunci: kawasan wisata; angkutan umum; trayek angkutan umum; tarif penumpang.

\section{PENDAHULUAN}

Daerah Istimewa Yogyakarta merupakan salah satu provinsi di Indonesia dengan jumlah objek wisata yang banyak dan menarik bagi wisatawan untuk dikunjungi. Dinas Pariwisata Daerah Istimewa Yogyakarta (2018) menyebutkan bahwa hingga tahun 2018 jumlah objek wisata adalah 186 lokasi, yang tersebar di 5 kota atau kabupaten, yaitu Kota Yogyakarta, Kabupaten Sleman, Kabupaten Bantul, Kabupaten Kulon Progo, dan Kabupaten Gunung Kidul. Peningkatan jumlah wisatawan mancanegara dan domestik terjadi setiap tahun, dan hingga tahun 2018 tercatat 600.102 orang wisatawan mancanegara dan 25.915.686 orang wisatawan domestik berkunjung. 
Menurut Peraturan Daerah Provinsi Daerah Istimewa Yogyakarta Nomor 1 Tahun 2019, Tentang Perubahan Atas Peraturan Daerah Provinsi Daerah Istimewa Yogyakarta Nomor 1 Tahun 2012, Tentang Rencana Induk Pembangunan Kepariwisataan Daerah Istimewa Yogyakarta Tahun 2012-2025, disebutkan bahwa terdapat 12 kawasan Daya Tarik Wisata (DTW) hingga saat ini, yang di antaranya adalah Kawasan Kaliurang-Merapi. Kawasan ini terletak di Utara Kabupaten Sleman, tepatnya di lereng Gunung Merapi. Lokasinya terkenal dengan potensi alam merapi, yang menjadikannya sebagai identitas kawasan ini.

Pemerintah DI Yogyakarta sedang membuat strategi untuk membangun pariwisata, yang di antaranya adalah meningkatkan kualitas dan kuantitas moda transportasi untuk mengakomodasi wisatawan menuju ke tempat wisata yang aman, nyaman, dan lancar. Sejalan dengan hal tersebut, peningkatan wisatawan yang berkunjung akan menyebabkan adanya kebutuhan untuk meningkatkan ketersediaan transportasi yang melayani objek-objek pariwisata yang ada.

Masalah transportasi yang dihadapi saat ini adalah ketidaktersediaan angkutan umum massal untuk menunjang kegiatan masyarakat. Tingginya minat wisatawan yang berkunjung tidak sejalan dengan transportasi publik yang disediakan. Angkutan umum di DI Yogyakarta yang beroperasi saat ini adalah Trans Jogja, dengan area pelayanan di Kota Yogyakarta dan sekitarnya. Terdapat pula Angkutan Antarkota Dalam Provinsi (AKDP) yang dapat dijadikan angkutan alternatif, untuk selanjutnya direncanakan trayek menuju ke objek-objek wisata yang ada. Tujuan penelitian ini adalah merencanakan trayek, untuk memenuhi kebutuhan angkutan dengan tarif yang sesuai bagi penumpang untuk menuju ke objek wisata di Kawasan Kaliurang-Merapi.

Menurut Peraturan Daerah Provinsi Daerah Istimewa Yogyakarta No. 1 Tahun 2019, Tentang Perubahan Atas Peraturan Daerah Provinsi Daerah Istimewa Yogyakarta No. 1 Tahun 2012, Tentang Rencana Induk Pembangunan Kepariwisataan Daerah Istimewa Yogyakarta Tahun 2012-2025, disebutkan bahwa pembangunan destinasi pariwisata daerah meliputi perwilayahan pariwisata, pengembangan dan pembangunan daya tarik wisata, pembangunan fasilitas kepariwisataan, pembangunan aksesibilitas dan/atau transportasi, pemberdayaan masyarakat melalui kepariwisataan, pembangunan investasi dibidang pariwisata, pemasarasan pariwisata, pembangunan kemitraan pemasaran pariwisata, pembangunan industri pariwisata, dan pembangunan kelembagaan kepariwisataan. Khusus untuk pembangunan aksesibilitas dan/atau transportasi wisata, terdapat arah kebijakan tersendiri yang akan dilakukan, yaitu pengembangan moda transporasi untuk mendukung pengembangan pariwisata, pengembangan sarana prasarana transportasi untuk mendukung pengembangan pariwisata, dan pengembangan sistem transportasi untuk mendukung sistem pariwisata.

\section{METODOLOGI PENELITIAN}

Penelitian ini dilakukan di kawasan wisata Kaliurang-Merapi, yang mana kawasan wisata tersebut terdiri atas 3 zona. Zona 1 meliputi Taman Rekreasi Anak Kaliurang, the 
World Landmark Merapi Park, dan Museum Gunung Merapi. Zona 2 meliputi Museum Ulen Sentalu, Volcano Tour, dan Taman Nasional Gunung Merapi. Zona 3 meliputi Bunker Kaliadem dan Desa Wisata Pentingsari.

Data yang dibutuhkan pada penelitian ini terdiri atas data primer dan data sekunder. Data primer diperoleh melalui observasi langsung di lokasi penelitian dan di instansi terkait. Data primer yang diperlukan adalah kondisi eksisiting kawasan pariwisata, potensi penumpang, kondisi jalan menuju ke lokasi agar angkutan wisata dimungkinkan untuk melewatinya, dan harga kendaraan yang digunakan untuk angkutan wisata, yang digunakan untuk menentukan biaya operasional kendaraan dan tarif. Sedangkan data sekunder diperoleh dengan melakukan studi pustaka terhadap penelitian terdahulu dan studi terhadap dokumen dari instansi terkait. Data sekunder yang diperlukan adalah peta lokasi objek wisata, peta jaringan jalan, jumlah pengunjung wisata di Kawasan Kaliurang-Merapi, serta data trayek AKDP dan lokasi terminal di Kabupaten Sleman.

\section{HASIL ANALISIS DAN PEMBAHASAN}

\section{Objek Wisata Kawasan Kaliurang-Merapi}

Kawasan wisata Kaliurang-Merapi dan sekitarnya terletak di Kabupaten Sleman, tepatnya di bagian utara, yaitu lereng Gunung Merapi, dimulai dari jalan yang menghubungkan kota Tempel, Turi, Pakem, Cangkringan, sampai dengan puncak Merapi. Wilayah ini merupakan wilayah sumber daya air dan ekowisata yang berorientasi pada kegiatan Gunung Merapi dan ekosistemnya. Jumlah pengunjung objek wisata di Kawasan KaliurangMerapi dan sekitarnya dapat dilihat pada Tabel 1 (Dinas Pariwisata Daerah Istimewa Yogyakarta, 2018).

Tabel 1 Jumlah Pengunjung Kasawasan Wisata Kaliurang-Merapi Tahun 2018

\begin{tabular}{lcc}
\hline Objek Wisata & $\begin{array}{c}\text { Jumlah Pengunjung } \\
\text { per tahun }\end{array}$ & $\begin{array}{c}\text { Jumlah Pengunjung } \\
\text { per hari }\end{array}$ \\
\hline The World Landmark Merapi Park & 164.500 & 451 \\
Museum Gunung Merapi & 270.904 & 742 \\
Volcano Tour & 530.146 & 1.452 \\
Taman Nasional Gunung Merapi & 111.883 & 307 \\
Bunker Kaliadem & 424.116 & 1.162 \\
Museum Ulen Sentalu & 96.155 & 263 \\
Taman Rekreasi Anak Kaliurang & 34.068 & 93 \\
Desa Wisata Pentingsari & 23.465 & 65 \\
\hline
\end{tabular}

Sumber: Dinas Pariwisata Daerah Istimewa Yogyakarta, 2019

Angkutan Antarkota Dalam Provinsi (AKDP) di Kabupaten Sleman saat ini masih tersedia, yang trayeknya telah ditetapkan dengan SK Gubernur Nomor 115/KEP/2005. Namun pada saat ini telah terjadi beberapa perubahan trayek, sehingga AKDP melayani hingga ke kawasan Kaliurang, yaitu trayek berkode 82, dengan rute Terminal Condong Catur-Gejayan-Jln. Terban-Jln. Kaliurang-Terminal Pakem. 


\section{Perencanaan Trayek}

Data pengunjung objek wisata di Kawasan Kaliurang-Merapi, yang terdapat pada Tabel 1, digunakan untuk merencanakan jaringan trayek ke objek wisata. Pada studi ini digunakan trayek AKDP, sehingga membuat trayek berkesinambungan.

Penentuan trayek dilakukan secara manual, dengan mengelompokan objek-objek wisata yang berdekatan menjadi beberapa zona. Titik awal dan titik akhir trayek yang direncanakan harus suatu terminal yang menjadi tempat singgah AKDP. Pembagian zona dan rute yang direncanakan dapat dilihat pada Tabel 2 dan Gambar 1.

Konsep trayek berbasis obyek wisata akan memberikan keuntungan dari sisi pariwisata dan dari sisi transportasi. Dari sisi pariwisata, trayek dapat meningkatkan jumlah kunjungan wisatawan ke suatu obyek, karena aksesibilitasnya menjadi mudah dan terjangkau. Sedangkan dari sisi transportasi, trayek dapat mengurangi kepadatan lalu lintas kendaraan pribadi yang berkunjung ke obyek wisata dan mengajak masyarakat menggunakan angkutan umu, sehingga kemacetan lalu lintas dapat dikurangi.

Tabel 2 Zona dan Rute Angkutan Wisata Kawasan Kaliurang-Merapi

\begin{tabular}{cll}
\hline Zona & Objek Wisata & Rute Angkutan \\
\hline Zona/Trayek 1 & Taman Rekreasi Anak Kaliurang & Jln. Pakem Kalasan-Jln. Boyong-Jln. \\
& The World Landmark Merapi Park & Museum Gunung Merapi-Jln. Boyong-Jln. \\
& Museum Gunung Merapi & Kaliurang-Jln. Pakem Kalasan \\
Zona/Trayek 2 & Museum Ulen Sentalu & Jln. Pakem Kalasan-Jln. Kaliurang-Jln. \\
& Volcano Tour & Astromulyo-Jln. Malangyudo-Jln. Tlogo \\
& Taman Nahional Gunung Merapi & Putri-Jln. Siaga-Jln. Tlogo Putri-Jln. \\
& & Malangyudo-Jln. Astromulyo-Jln. \\
Zona/Trayek 3 & Bunker Kaliadem & Kaliurang-Jln. Pakem Kalasan \\
& Desa Wisata Pentingsari & Jln. Pakem Kalasan-Jln. Raya Merapi Golf- \\
& & Jln. Bebeng-Jln. Pakem Kalasan \\
\hline
\end{tabular}

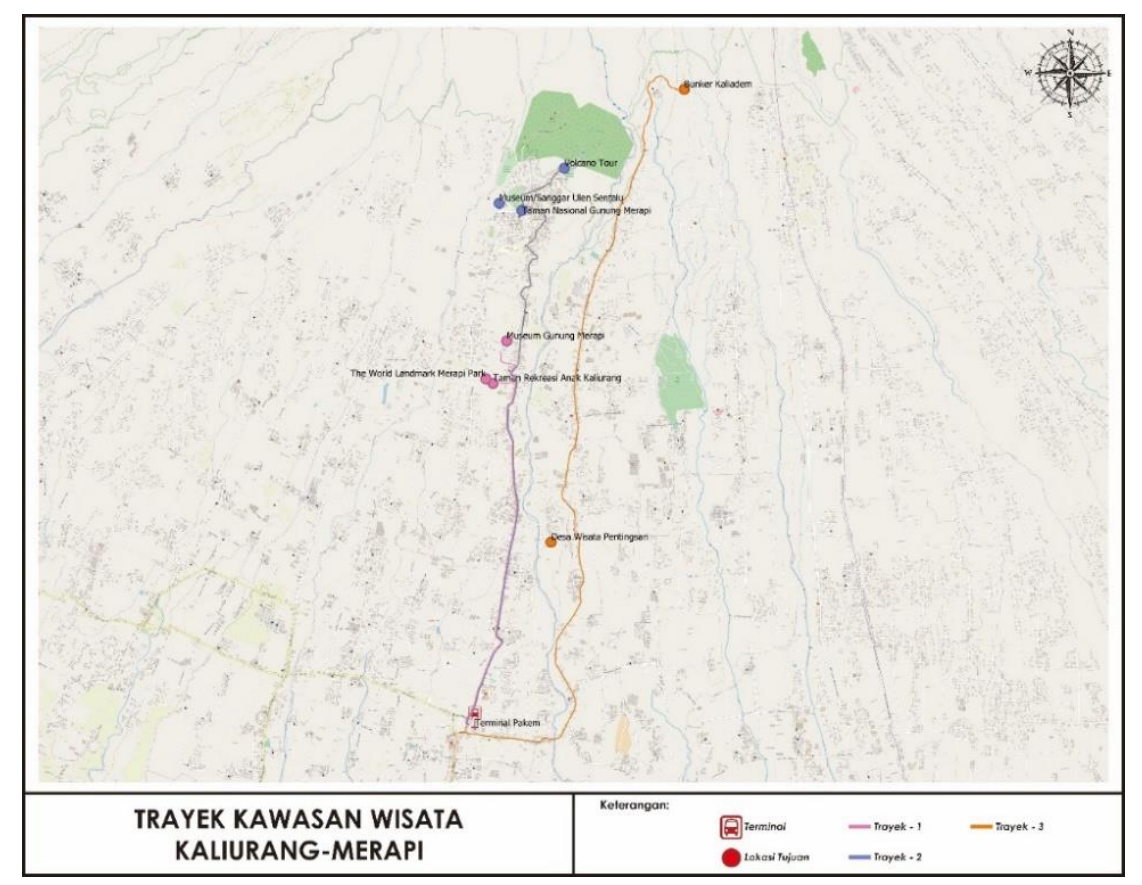

Gambar 1 Trayek Angkutan Wisata Kawasan Kaliurang-Merapi 


\section{Perencanaan Angkutan Wisata}

Basuki dan Setiadi (2015) menyebutkan bahwa terdapat hal yang perlu diperhatikan dalam melakukan model angkutan pariwisata Daerah Istimewa Yogyakarta, yaitu bus angkutan khusus pariwisata dilakukan dengan pengadaan bus untuk jalur-jalur objek wisata yang potensial secara teratur. Beberapa asumsi dan batasan yang digunakan untuk memudahkan perhitungan adalah bahwa jam operasional tempat wisata adalah 8 jam, yaitu jam 08.00 WIB hingga jam 17.00 WIB. Selain itu, potensi penumpang yang digunakan didasarkan pada data sekunder yang terdapat pada Tabel 1, dengan menggunakan kategori, yaitu: (a) potensi pengguna optimis, yaitu jumlah penumpang yang menggunakan angkutan umum dianggap sebesar $75 \%$ dari total pengujung per hari, (b) potensi pengguna moderat, yaitu jumlah penumpang yang menggunakan angkutan umum dianggap sebesar 50\% terhadap total pengunjung per hari, dan (c) potensi pengguna pesimis, yaitu jumlah penumpang yang menggunakan angkutan umum dianggap sebesar $25 \%$ terhadap total pengunjung per hari. Berdasarkan ketiga kategori potensi penumpang yang digunakan potensi penumpang di Kawasan Kaliurang-Merapi pada tahun 2018 disajikan pada Tabel 3.

Pada studi ini, jenis kendaraan yang digunakan diasumsikan adalah bus sedang Hino Duotro 130 MDBL Karoseri Aduputro. Bus ini memiliki kapasitas tempat duduk 29 kursi penumpang, 1 kursi supir, dan 1 kursi kondektur, dengan harga mesin dan chasis Rp302.800.000,00 dan harga karoseri Rp275.000.000,00, sehingga total harga bus adalah Rp577.800.000,00, dan bila ditambah PPN sebesar 10\% menjadi Rp635.580.000,00. Kecepatan kendaraan rencana adalah $40 \mathrm{~km} / \mathrm{jam}$.

Perhitungan jumlah kendaraan yang diperlukan untuk mengangkut pengunjung wisata Kawasan Kaliurang-Merapi mengacu pada Keputusan Direktur Jenderal Perhubungan Darat Nomor SK.687/AJ.206/DRJD/2002, tentang Pedoman Teknis Penyelenggaraan Angkutan Penumpang Umum di Wilayah Perkotaan dalam Trayek Tetap dan Teratur. Hasil perhitungan dapat dilihat pada Tabel 4.

Tabel 3 Jumlah Potensi Pengunjung Angkutan Wisata Kawasan Kaliurang-Merapi

\begin{tabular}{|c|c|c|c|c|}
\hline \multirow{2}{*}{$\begin{array}{l}\text { Nama } \\
\text { Trayek }\end{array}$} & \multirow{2}{*}{ Objek Wisata } & \multicolumn{3}{|c|}{ Potensi Pengunjung/Jam } \\
\hline & & Optimis & Moderat & Pesimis \\
\hline \multirow[t]{4}{*}{ Trayek 1} & Taman Rekreasi Anak Kaliurang & 9 & 6 & 3 \\
\hline & The World Landmark Merapi Park & 42 & 28 & 14 \\
\hline & Museum Gunung Merapi & 70 & 46 & 23 \\
\hline & Total & 121 & 80 & 40 \\
\hline \multirow[t]{4}{*}{ Trayek 2} & Museum Ulen Sentalu & 25 & 16 & 8 \\
\hline & Volcano Tour & 136 & 91 & 45 \\
\hline & Taman Nasional Gunung Merapi & 29 & 19 & 10 \\
\hline & Total & 190 & 126 & 63 \\
\hline \multirow[t]{3}{*}{ Trayek 3} & Bunker Kaliadem & 109 & 73 & 36 \\
\hline & Desa Wisata Pentingsari & 6 & 4 & 2 \\
\hline & Total & 115 & 77 & 38 \\
\hline
\end{tabular}


Tabel 4 Frekuensi dan Jumlah Kebutuhan Angkutan Wisata Kawasan Kaliurang-Merapi

\begin{tabular}{cccccc}
\hline $\begin{array}{c}\text { Nama Trayek } \\
\text { dan Potensi } \\
\text { Penumpang }\end{array}$ & $\begin{array}{c}\text { Jarak } \\
(\mathrm{km})\end{array}$ & $\begin{array}{c}\text { Waktu } \\
\text { Sirkulasi } \\
\text { (menit) }\end{array}$ & $\begin{array}{c}\text { Headway } \\
\text { (menit) }\end{array}$ & $\begin{array}{c}\text { Frekuensi } \\
\text { (rit/jam) }\end{array}$ & $\begin{array}{c}\text { Jumlah } \\
\text { Kendaraan } \\
\text { (unit) }\end{array}$ \\
\hline Trayek 1 & & & & & \\
Optimis & 14,0 & 24 & 14 & 4 & 2 \\
Moderat & 14,0 & 24 & 20 & 3 & 2 \\
Pesimis & 14,0 & 24 & 40 & 2 & 1 \\
Trayek 2 & & & & & \\
Optimis & 20,3 & 35 & 9 & 7 & 3 \\
Moderat & 20,3 & 35 & 13 & 5 & 2 \\
Pesimis & 20,3 & 35 & 25 & 2 & 3 \\
Trayek 3 & & & & 4 & 2 \\
Optimis & 23,6 & 41 & 15 & 3 & 1 \\
Moderat & 23,6 & 41 & 20 & 2 & \\
Pesimis & 23,6 & 41 & 40 & & \\
\hline
\end{tabular}

\section{Biaya Operasional Kendaraan}

Menurut Keputusan Menteri Perhubungan Nomor KM. 89 Tahun 2002, tentang Mekanisme Penetapan Tarif dan Formula Perhitungan Biaya Pokok Angkutan Penumpang dengan Mobil Bus Umum Antar-Kota Kelas Ekonomi, dalam menghitung biaya operasional kendaraan, perlu dilakukan pengelompokan biaya menurut hubungannya dengan produksi jasa yang dihasilkan. Biaya operasional kendaraan untuk rencana angkutan wisata di Kawasan Kaliurang-Merapi dapat dilihat pada Tabel 5.

Tabel 5 Biaya Operasional Kendaraan Angkutan Wisata Kawasan Kaliurang-Merapi

\begin{tabular}{cccc}
\hline & \multicolumn{3}{c}{ Biaya per BUS-KM } \\
\cline { 2 - 4 } Komponen & $\begin{array}{c}\text { Biaya } \\
\text { Tidak Langsung } \\
(\mathrm{Rp})\end{array}$ & $\begin{array}{c}\text { Biaya } \\
\text { Langsung } \\
(\mathrm{Rp})\end{array}$ & $\begin{array}{c}\text { Biaya } \\
\text { Pokok } \\
(\mathrm{Rp})\end{array}$ \\
\hline Trayek 1 & & & \\
Optimis & 8.939 & 4.242 & 13.181 \\
Moderat & 9.004 & 4.469 & 13.473 \\
Pesimis & 11.767 & 7.303 & 19.070 \\
Trayek 2 & & & \\
Optimis & 5.318 & 3.701 & 9.019 \\
Moderat & 5.692 & 3.965 & 9.657 \\
Pesimis & 12.292 & 5.998 & 18.290 \\
Trayek 3 & & & \\
Optimis & 4.884 & 3.617 & 8.501 \\
Moderat & 5.481 & 3.909 & 9.390 \\
Pesimis & 13.848 & 6.125 & 19.973 \\
\hline
\end{tabular}

\section{Perencanaan Tarif Penumpang}

Perhitungan tarif angkutan mengacu pada Keputusan Direktur Jenderal Perhubungan Darat Nomor SK.687/AJ.206/DRJD/2002, tentang Pedoman Teknis Penyelenggaraan Angkutan Penumpang Umum di Wilayah Perkotaan dalam Trayek Tetap dan Teratur. Formula yang digunakan untuk menentukan tarif adalah:

$$
\begin{aligned}
& \text { Tarif pokok }=\frac{\text { Total Biaya Pokok }}{\text { Load Factor } \times \text { Kapasitas Angkutan }} \\
& \text { Tarif penumpang }=\text { Tarif Pokok } \times \text { Jarak }
\end{aligned}
$$


Dengan menggunakan rumus tersebut dilakukan perhitungan tarif, yang hasilnya dapat dilihat pada Tabel 6.

Tabel 6 Penentuan Tarif Penumpang

\begin{tabular}{cccccr}
\hline $\begin{array}{c}\text { Nama Trayek } \\
\text { dan Potensi } \\
\text { Penumpang }\end{array}$ & $\begin{array}{c}\text { Jarak } \\
(\mathrm{km})\end{array}$ & $\begin{array}{c}\text { Potensi } \\
\text { Penumpang } \\
\text { (orang/bus) }\end{array}$ & $\begin{array}{c}\text { BOK } \\
(\mathrm{Rp} / \mathrm{bus}-\mathrm{km})\end{array}$ & $\begin{array}{c}\text { Tarif Pokok } \\
(\text { Rp/pnp-km) }\end{array}$ & $\begin{array}{r}\text { Tarif penumpang } \\
\text { (Rp/pnp-trip) }\end{array}$ \\
\hline Trayek 1 & & & & & \\
Optimis & 14,0 & 28 & 13.181 & 471,00 & $7.000,00$ \\
Moderat & 14,0 & 27 & 13.473 & 499,00 & $7.000,00$ \\
Pesimis & 14,0 & 27 & 19.070 & 706,00 & $10.000,00$ \\
Trayek 2 & & & & & \\
Optimis & 20,3 & 29 & 9.019 & 311,00 & $7.000,00$ \\
Moderat & 20,3 & 26 & 9.657 & 371,00 & $8.000,00$ \\
Pesimis & 20,3 & 26 & 18.290 & 703,00 & $15.000,00$ \\
Trayek 3 & & & & & $8.000,00$ \\
Optimis & 23,6 & 28 & 8.501 & 304,00 & $9.000,00$ \\
Moderat & 23,6 & 26 & 9.390 & 361,00 & $19.000,00$ \\
Pesimis & 23,6 & 25 & 19.973 & 799,00 & \\
\hline
\end{tabular}

\section{KESIMPULAN}

Pada studi ini dilakukan perencanaan angkutan menuju Kawasan Wisata KaliurangMerapi, Provinsi Daerah Istimewa Yogyakarta. Terdapat 3 trayek yang direncanakan untuk melayani Kawasan Wisata Kaliurang-Merapi yaitu Trayek 1 dengan panjang lintasan 14 km, Trayek 2 dengan panjang lintasan 20,3 km, dan Trayek 3 dengan panjang lintasan 23,6 km. Trayek-trayek tersebut terkoneksi dengan AKDP yang melayani hingga Terminal Pakem, lalu melanjutkannya dengan angkutan menuju Kawasan Wisata Kaliurang-Merapi, dengan rute trayek AKDP adalah Terminal Condong Catur-Gejayan-Jln. Terban-Jln. KaliurangTerminal Pakem.

Waktu pelayanan angkutan adalah 8 jam, dengan menggunakan bus sedang tipe Hino Duotro 130 MDBL yang berkapasitas 29 penumpang. Kecepatan kendaraan direncanakan $40 \mathrm{~km} / \mathrm{jam}$ dan menggunakan asumsi load factor yang mendekati $100 \%$ terhadap potensi jumlah penumpang optimis (75\%), potensi jumlah penumpang moderat $(50 \%)$, dan potensi jumlah penumpang pesimis $(25 \%)$. Tarif yang diusulkan per penumpang per trip untuk trayek-trayek di Kawasan Wisata Kaliurang-Merapi adalah Rp7.000-Rp10.000 untuk Trayek 1, Rp7.000-Rp15.000 untuk Trayek 2, dan Rp8.000-19.000 untuk Trayek 3.

\section{DAFTAR PUSTAKA}

Basuki, I. dan Setiadi, A. 2015. Potensi Angkutan Umum Pariwisata di Daerah Istimewa Yogyakarta. The 18th FSTPT International Symposium, Unversitas Negeri Lampung, Bandar Lampung. 
Dinas Pariwisata Daerah Istimewa Yogyakarta. 2018. Statistik Kepariwisataan 2018. Yogyakarta.

Direktorat Jenderal Perhubungan Darat. 2002. Keputusan Direktur Jenderal Perhubungan Darat Nomor SK.687/AJ.206/DRJD/2002, tentang Pedoman Teknis Penyelenggaraan Angkutan Penumpang Umum di Wilayah Perkotaan dalam Trayek Tetap dan Teratur. Kementerian Perhubungan. Jakarta.

Kementerian Perhubungan. 2002. Keputusan Menteri Perhubungan Nomor KM. 89 Tahun 2002, tentang Mekanisme Penetapan Tarif dan Formula Perhitungan Biaya Pokok Angkutan Penumpang dengan Mobil Bus Umum Antar-Kota Kelas Ekonomi. Jakarta.

Pemerintah Daerah Istimewa Yogyakarta. 2012. Peraturan Daerah Provinsi Daerah Istimewa Yogyakarta Nomor 1 Tahun 2012, tentang Rencana Induk Pembangunan Kepariwisataan Daerah Provinsi Daerah Istimewa Yogyakarta Tahun 2012-2025. Yogyakarta.

Pemerintah Daerah Istimewa Yogyakarta. 2019. Peraturan Daerah Provinsi Daerah Istimewa Yogyakarta Nomor 1 Tahun 2019, tentang Perubahan Atas Peraturan Daerah Provinsi Daerah Istimewa Yogyakarta Nomor 1 Tahun 2012 tentang Rencana Induk Pembangunan Kepariwisataan Daerah Istimewa Yogyakarta Tahun 20122025. Yogyakarta. 